\title{
The Role of Active and Passive Fire Protection Techniques in Fire Control, Suppression and Extinguishment
}

\author{
A. TEWARSON and M. M. KHAN \\ Factory Mutual Research Corporation \\ 1151 Boston-Providence Turnpike \\ Norwood, Massachusetts 02062, USA
}

\section{ABSTRACT}

In this paper modes of action of passive fire protection agents, incorporated chemically into materials and products, are discussed in terms of resistance to ignition and fire propagation and reduction in heat release rate. The effectiveness of these agents in large-scale fires, to enhance the ease of fire control, suppression and extinguishment by water, in warehouses is evaluated. All the experiments were performed in the Factory Mutual Research Corporation's $50 \mathrm{~kW}-, 500 \mathrm{~kW}$ - and 10,000 kW-Scale Flammability Apparatuses.

The modes of action of the agents appear to be chemical in nature. The ratio of the yields of $\mathrm{CO}$ to $\mathrm{CO}_{2}$ increases and the chemical heat of combustion decreases with an increase in the amount of the agent incorporated into the materials and products.

In the Large-Scale Warehouse Simulation Tests, corrugated paper cartons treated with a passive fire protection agent, identified as $A$, and a plastic product treated with another agent, identified as B, were found to significantly reduce water demand for fire control, suppression and extinguishment.

KEYWORDS: Suppression, Specialized Fire Problems, Translation of Research into practice, Fire Chemistry

\section{NOMENCLATURE}

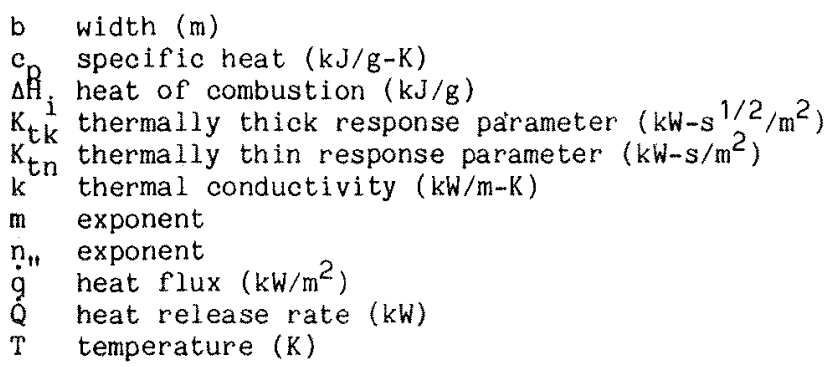




$\begin{array}{ll}t & \text { time }(\mathrm{s}) \\ v & \text { velocity }(\mathrm{m} / \mathrm{s}) \\ Y & \text { yield }(\mathrm{g} / \mathrm{g}) \\ \rho & \text { density }\left(\mathrm{g} / \mathrm{m}^{3}\right) \\ \delta & \text { thickness }(\mathrm{m})\end{array}$

\section{Superseripts}

- per unit of time $\left(\bar{s}^{1}\right)$
per unit area $\left(\bar{m}^{2}\right)$

\section{Subscripts}

a ambient
cr critical
chem chemical
con convective
e external
g gas
ig ignition
sf initial surface

\section{INTRODUCTION}

Numerous fires have occurred involving products used in residential, commercial and industrial occupancies, creating hazards to life and property due to generation of heat and chemical compounds. Hazards associated with the generation of heat are defined as thermal hazards; and those associated with the generation of chemical compounds are defined as non-thermal hazards $[1,2]$. In order to reduce and/or eliminate thermal and non-thermal hazards, two types of fire protection techniques are used: 1) active fire protection, and 2) passive fire protection. Active fire protection techniques utilize the principle of suppression and/or extinguishment of a growing fire by applying agents to the fire. Application of water to growing fires through sprinklers is one of the most widely used effective active fire protection techniques $[3,4]$. Passive fire protection techniques, on the other hand, utilize the principle of: 1) providing resistance to ignition and fire propagation, and 2) reducing the amounts of heat and chemical compounds generated in fires. Various types of passive fire protection techniques are used, such as changes in chemical structures, use of fire retardants, coatings and fire barriers, changes in product configurations, arrangements and physical dimensions and others.

There is a growing interest in developing effective passive fire protection techniques, complementary to the active fire protection techniques. In this paper an attempt has been made to elucidate some aspects of the mode of action of the passive fire protection agents.

\section{CONCEPTS}

\section{Resistance to Ignition and Fire Propagation}

The resistance to ignition and fire propagation depends on three parameters 1) Critical Heat Elux (CHF) which is the minimum heat flux at or below which there is no ignition, 2) Thermal Response Parameter (TRP) which is the time taken by the material to absorb heat to raise its temperature to ignition temperature [1], and 3 ) heat release rate [1].

The relationship between time to ignition and external heat flux is expressed as follows [5]:

1) For Thermally Thick Materials

$$
t_{i g}^{-1 / 2}=(4 / \pi)^{1 / 2} \dot{q}_{e}^{11} /\left(T_{i g}-T_{S f}\right)\left(k_{p c}\right)^{1 / 2}
$$


2) For Thermally Thin Materials

$t_{i g}^{-1}=\dot{q}_{e}^{\prime \prime} /\left(T_{i g}-T_{s f}\right)\left(\rho c_{p} \delta\right)$

where $t_{i g}$ is the time to ignition $(\mathrm{s}) ; \dot{q}_{e}$ is the external heat flux $\left(\mathrm{kW} / \mathrm{m}^{2}\right)$; $\mathrm{T}_{\mathrm{ig}}$ is the ignition temperature $(K), \mathrm{T}_{\mathrm{Sf}}$ is the initial surface temperature $\left(\mathrm{K}^{9} ; \mathrm{k}\right.$ is the thermal conductivity $(\mathrm{kW} / \mathrm{m}-\mathrm{K}) ; \mathrm{c}_{\mathrm{p}}$ is the specific heat $(\mathrm{kJ} / \mathrm{g}-$ $\mathrm{K}) ; \rho$ is the density $\left(\mathrm{g} / \mathrm{m}^{3}\right)$ and $\delta$ is the physical thickness of the material $(\mathrm{m})$. The denominators in Eqs.(1) and (2) are the Thermal Response Parameters for thermally thick and thip materials, expressed as Thermally Thick Response Parameter, $k_{t k}\left(k W-s / 2 / m^{2}\right)$ and Thermally Thin Response Parameter, $\mathrm{K}_{\mathrm{tn}},\left(\mathrm{kW}-\mathrm{s} / \mathrm{m}^{2}\right)$, respectively $[1]$.

The fire propagation velocity for constant heat flux to the surface is expressed as $[1,6]$ :

1) For Thermally Thick Materials

$v^{1 / 2}$ a $\mathrm{K}_{\mathrm{tk}}^{-1}$

2) For Thermally Thin Materials

$\mathrm{v} \alpha \mathrm{K}_{\mathrm{tn}}^{-1}$

where $\mathrm{v}$ is the fire propagation velocity $(\mathrm{m} / \mathrm{s})$.

Heat Release Rate

For sustained fire propagation beyond the ignition zone, the heat flux from the flame or from other external or internal heat sources should be greater than the CHF and time of exposure must satisfy the TRP. For cases where flame is the only heat source, the flame heat flux beyond the ignition zone is a function of the heat release rate $[6,7]$. Thus, for a material,

$v a(\dot{Q} / b)^{n}$

where $\dot{Q}$ is the heat release rate $(\mathrm{kW}) ; \mathrm{b}$ is the width of the materials (m) and $\mathrm{n}$ is an exponent.

From Eqs. (3) and (5), for thermally thick materials,

$\mathrm{v}^{1 / 2} \alpha(\dot{\mathrm{Q}} / \mathrm{b})^{\mathrm{m}} / \mathrm{K}_{\mathrm{tk}}$

where $\mathrm{m}$ is an exponent; and, from Eqs. (4) and (5), for thermally thin materials,

$v$ a $(\dot{Q} / \mathrm{b})^{\mathrm{n}} / \mathrm{K}_{\mathrm{tn}}$

The values of $v$ decrease as $K_{t k}$ or $K_{t n}$ values increase and/or $\dot{Q}$ values decrease, which can be accomplished by passive fire protection techniques complementary to the active fire protection techniques. This concept has recently been utilized for electrical cables [7-9], where cables with effective passive fire protection through chemical modifications and fire retardants, defined as Group 1 cables, were found to have difficulty in sustaining fire propagation beyond the ignition zone and thus do not need active fire protection [9]. 


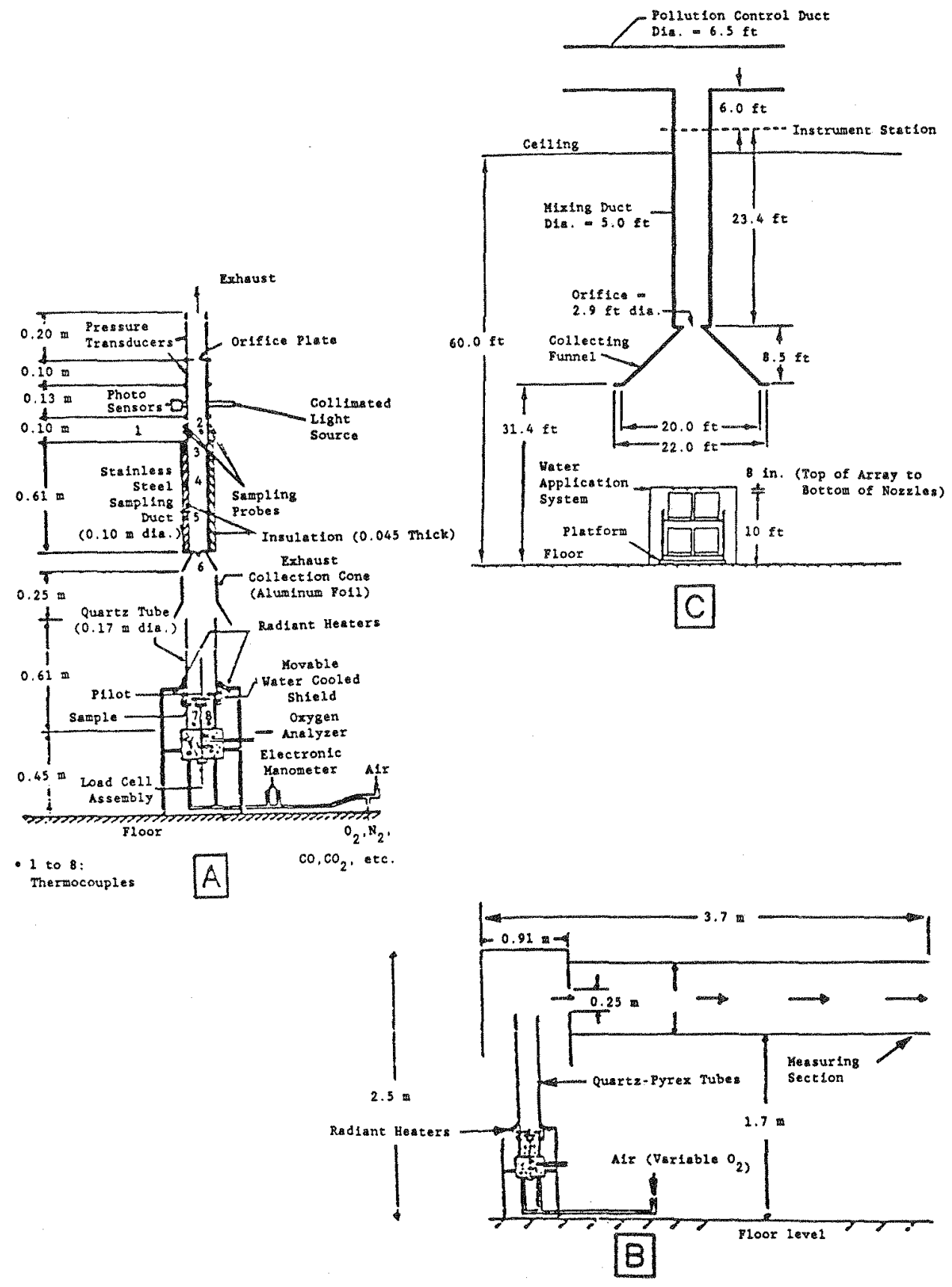

Figure 1. Flammability Apparatuses Used in the Experiments: A) 50kW-Scale; B) $500 \mathrm{~kW}$-Scale; and C) $10,000 \mathrm{~kW}$-Scale. 


\section{EXPERIMENTS}

\section{Quantification of CHE and TRP}

For the quantification of $\mathrm{CHF}$ and TRP, ignition experiments are performed in our $50 \mathrm{~kW}$-Scale Flammability Apparatus shown in Fig. $1 \mathrm{~A}$. In the experiments, about $100 \times 100 \mathrm{~mm}$ horizontal samples with thicknesses varying from about 3 to $100 \mathrm{~mm}$ are used and time to ignition was measured as a function of external heat flux.

The experimental data satisfy eqs. (1) and (2) and can be noted in Fig. 2 for $0.006 \mathrm{~m}$ thick corrugated paper sheets, which behave as thermally thin materials, and in Fig. 3 for $0.025 \mathrm{~m}$ thick polymethylmethacrylate sheet, which behaves as a thermally thick material. From the slopes of the lines, $K_{t n}$ and $K_{t k}$ values are determined. Extensive data for CHF and $K_{t n}$ and $K_{t k}$ values for various materials have been reported $[1,7,10,11]$.

\section{Quantification of Heat Release Rate}

For the quantification of heat release rate, three Apparatuses shown in Figure 1 are used. For small-scale experiments, the $50 \mathrm{~kW}$ - and $500 \mathrm{~kW}$-Scale Flammability Apparatuses, shown in Figs. $1 \mathrm{~A}$ and $1 \mathrm{~B}$ respectively, are used. For large-scale experiments, the $10,000 \mathrm{~kW}$-Scale Flammability Apparatus shown in Fig. 1C, is used.

In the experiments measurements are made for the total flow of the mixture of fire products and air, concentrations of various chemical compounds, gas temperature, and optical transmission through smoke. Chemical heat release rate, associated with the chemical reactions, is calculated from the generation rates of $\mathrm{CO}$ and $\mathrm{CO}_{2}$ and consumption rate of $\mathrm{O}_{2}[1,2]$.

Convective heat release rate, which is the component of the chemical heat release rate associated with the flow of hot fire products away from the chemical reaction zone, is calculated from the total mass flow rate, specific heat and gas temperature above ambient.

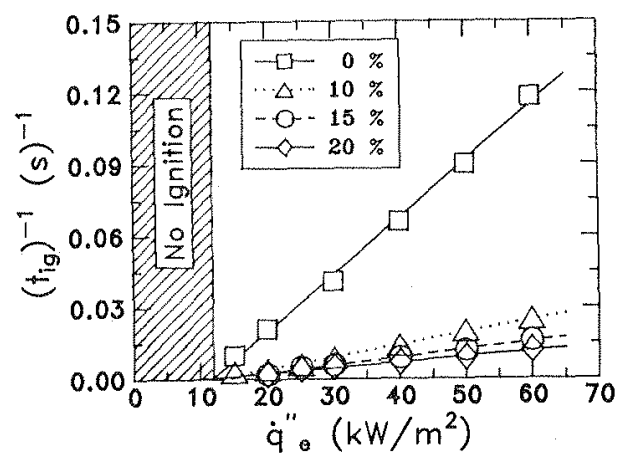

Figure 2. Time to Piloted Ignition Versus External Heat Flux for $0.006 \mathrm{~m}$ Thick Treated and Untreated Corrugated Paper Sheet. Legend Shows Weight Percent of the Passive Fire Protection Agent A.

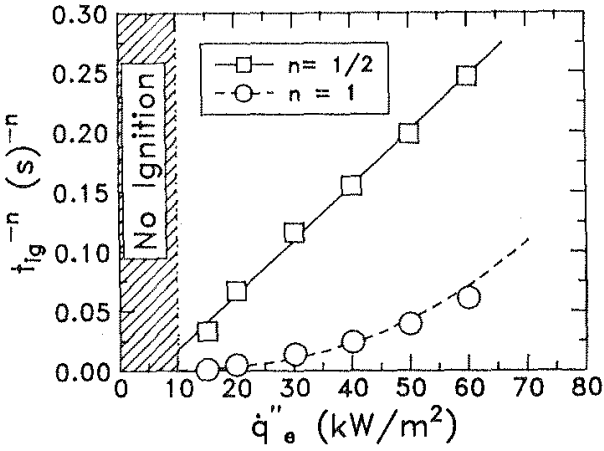

Figure 3. Time to Piloted Ignition Versus External Heat Flux for $0.025 \mathrm{~m}$ Thick Polymethylmethacrylate Sheet. Figure Taken from Ref. 1. 


\section{Quantification in Small-Scale Experiments}

In the experiments in our $50 \mathrm{~kW}$ - and $500 \mathrm{~kW}$-Scale Flammability Apparatuses, materials are used either as sheets or as sample "commodities" consisting of $0.1 \times 0.1 \times 0.1 \mathrm{~m}$ corrugated paper boxes with and without contents. In the experiments, one to eight corrugated boxes, separated by about $0.013 \mathrm{~m}$, are used on single and double racks. The boxes are ignited at the lower edges and corner by a match.

Experiments are performed with or without external heat flux. For simulation of large-scale flame radiation conditions [13], experiments are performed under forced flow conditions, where oxygen concentration of inlet air is increased to 30 to $40 \%$. For fire suppression/extinguishment experiments, Halon and other gaseous agents are added to the inlet air. Water, on the other hand, is applied by an applicator located about $10 \mathrm{~mm}$ above the top of the commodity, such that there is $100 \%$ penetration of water to the burning surface.

\section{Quantification in Large-Scale Experiments}

In the tests in the $10,000 \mathrm{~kW}$-Scale Flammability Apparatus the commodities consist of $0.53 \times 0.53 \times 0.53$ in corrugated paper cartons, containing various types of products made from inert materials, metals and natural and synthetic polymeric materials [14-16]. The commodities are tested in eight pallet loads. Each pallet load consists of eight cartons, placed on top of a wooden pallet. The eight pallet loads are arranged in a 2 wide by 2 deep by 2 high configuration, ( $2 \times 2 \times 2$ array), where each pallet load is separated by about $0.15 \mathrm{~m}$ from each other $[14-16]$.

The commodities are ignited at four inside corners of the bottom cartons in the center. Water is applied by an applicator about $0.3 \mathrm{~m}$ above the top $[14-16]$.

On the basis of heat release rates and water demand for fire suppression/extinguishment $[15,16]$, the commodities are classified as Class I to IV and Groups B and A plastics ${ }^{(a)}$.

\section{EXPERIMENTAL RESULTS}

\section{Small-Scale Experiments}

Several passive fire protection agents, incorporated into various polymeric materials and corrugated paper sheets and boxes, have been examined in our $50 \mathrm{~kW}-, 500 \mathrm{~kW}$ - and $10,000 \mathrm{~kW}-$ Scale Flammability Apparatuses. In this paper, we have selected two passive fire protection agents, one for the corrugated paper sheets and boxes, identified as agent $A$, and the other for "Group B plastic commodity" identified as agent B. The active fire protection agent is water.

\footnotetext{
(a) Class I: glass jars in compartmented cartons; Class II: metal-lined double triwall cartons; Class III: paper cups in compartmented cartons; Class IV: polystyrene and paper cups in compartmented cartons; Group A plastics: polystyrene cups in compartmented cartons; Group B plastics: polyethylene cups in compartmented cartons.
} 


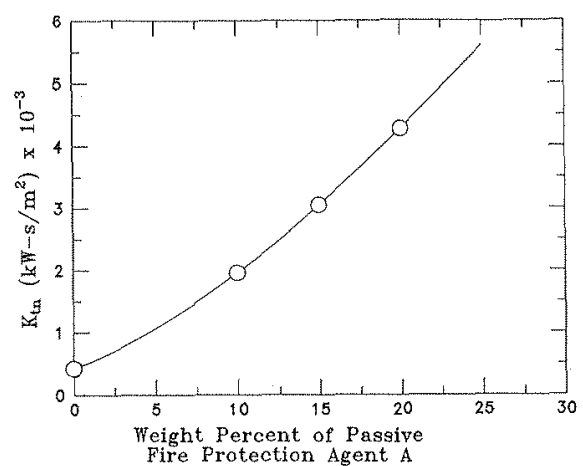

Eigure 4. Thermally Thin Response Parameter Versus Weight Percent of Passive Fire Protection Agent A Applied to $0.006 \mathrm{~m}$ Thick Corrugated Paper Sheet.

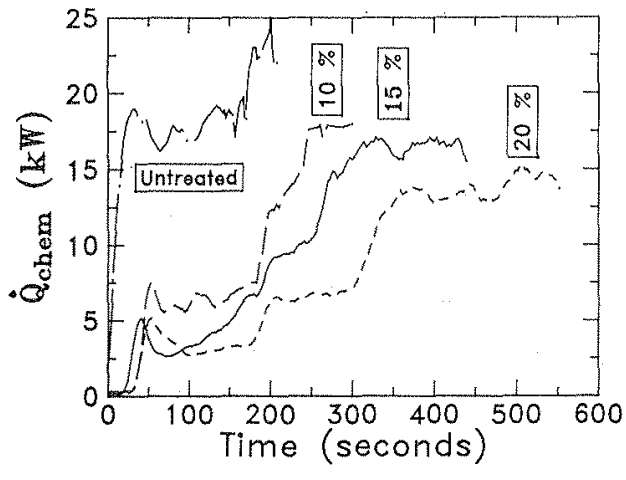

Figure 5. Chemical Heat Release Rate for $0.01 \times 0.01 \times 0.01 \mathrm{~m}$ Treated and Untreated Corrugated Paper Boxes with Polystyrene. Conditions: Array $1 \times 1$ $x$ 2; Forced Air Flow Velocity $=0.071$ $\mathrm{m} / \mathrm{s}$; Oxygen Concentration $=30 \%$; External Heat Flux $=20 \mathrm{~kW} / \mathrm{m}^{2}$; Treatment $=$ Passive Fire Protection Agent $A$.

The data for time to piloted ignition, in Fig. 2 satisfy Eq. (2). The $K_{t n}$ values derived from these ignition data are plotted in $F i g .4$ against the amount of agent $A$. The plot shows that $K_{t}$ values increase as a power function of the weight percent of agent $A$. These results in conjunction with Eq. 4, thus suggest that fire propagation velocity, $v$, is expected to decrease with increase in the amount of agent $A$. Incorporation of about 10 to $20 \%$ by weight of agent $A$ in corrugated paper boxes, for use in warehouse storage of products, therefore, is expected to enhance the ease of fire control, suppression and extinguishment by water as well as by other agents.

Fig. 5 shows the chemical heat release rate profiles for $0.01 \times 0.01 \times 0.01$ $m$ corrugated paper boxes with and without the agent $A$. In the experiments two boxes were used, one on top of the other on a rack separated by about $0.013 \mathrm{~m}$. In the experiments, the lower box was exposed to an external heat flux of $20 \mathrm{~kW} / \mathrm{m}^{2}$. The experiments were performed under forced air flow conditions with an air velocity of $0.071 \mathrm{~m} / \mathrm{s}$ and oxygen concentration of $30 \%$.

Fig 5 shows the chemical heat release rate profiles for boxes with strips of PS cups (40\% by weight) which are Group A plastics. As can be noted, fire propagation is very rapid for untreated corrugated boxes and the peak value of $\dot{Q}_{\text {onem }}$ is highest. For treated boxes, the fire propagation remains slow, belng slowest for the corrugated boxes with $20 \%$ by weight of agent $A$, although all of the boxes contain "Group A plasties commodity". It thus appears that due to slower initial fire propagation for the boxes treated with agent A containing "Group A plastics commodity", water is expected to be effective at a lower application rate than the "Group A plastics commodity". This prediction has been validated in the large-scale tests in the $10,000 \mathrm{~kW}-$ Scale Flammability Apparatus as discussed in the following section. 
The mode of action of agent $A$ in reducing the heat release rate appears to be chemical in nature. Fig. 6 shows a plot of average ${ }^{*}{ }^{\mathrm{CO}}{ }^{\prime} \mathrm{Y}_{\mathrm{CO}}$ values versus the weight percent of agent $A$. The ratio increases with the amount of agent $A$, which is an indication that combustion becomes less efficient, resulting in the decrease in the average chemical heat of combustion* ${ }^{*}$, as can be noted in the figure.

We have also examined the passive fire protection agent $B$. This agent reduces the chemical heat release of the sample of "Group $B$ plastic commodity" by about $1 / 4 \mathrm{th}$, and increases $K_{t n}$ value by about ten times. Its actions are very similar to those of agent $A$, and thus is also expected to be effective in enhancing the ease of fire control, suppression and extinguishment by water and by other agents. The effectiveness of agent $B$ has been validated in the large-scale tests in the 10,000 kW-Scale Elammability Apparatus as discussed in the following section.

\section{Large-Scale Experiments}

Chemical and convective heat release rates at 65,135 and $203 \mathrm{ml} / \mathrm{m}^{2}-\mathrm{s}$ $\left(0.1,0.2\right.$ and $\left.0.3 \mathrm{gpm} / \mathrm{ft}^{2}\right)$ of water application rates have been measured for "Class I to IV and plastics commodities" in the 10,000 kW-Scale Flammability Apparatus [15]. In this paper we have used the one minute average of the peak chemical and convective heat release rates reported in Ref. 15, to establish generalized relationships between heat release rates and water application rates. All the data presented in this paper are calculated from these generalized relationships.

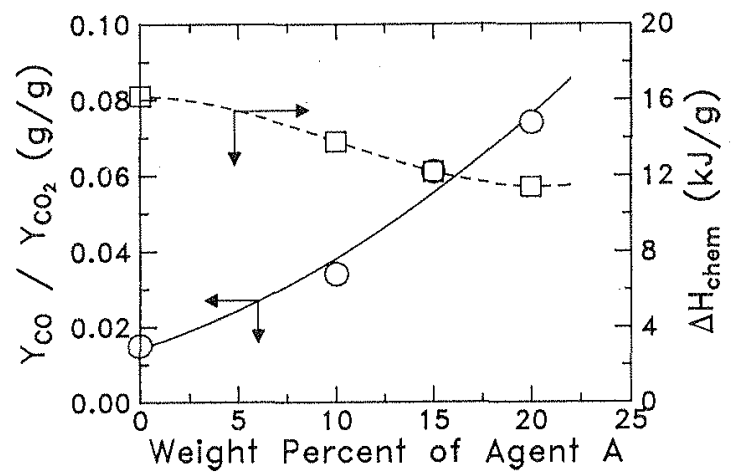

Figure 6. Ratio of the Yields of $\mathrm{CO}$ and $\mathrm{CO}_{2}$ and Chemical Heat of Combustion Versus the Weight Percent of Passive Fire Protection Agent $A$ for Treated and Untreated $0.01 \times 0.01 \times 0.01 \mathrm{~m}$ Corrugated Boxes in a $1 \times 1 \times 2$ Array. Conditions: Forced Air Flow Velocity $=0.071 \mathrm{~m} / \mathrm{s} ;$ Oxygen Concentration = $30 \%$; External Heat flux $=20 \mathrm{~kW} / \mathrm{m}^{2}$.

* $Y$ is the average yield, defined as the ratio of the total amount of the product generated to the total amount of the material vaporized.

* Average chemical heat of combustion is defined as the ratio of the total chemical energy generated to the total amount of material vaporized. 
Figs. 7 and 8 show the calculated chemical and convective heat release rates at various water application rates. The heat release rate decreases with increase in the water application rate. For effective fire control, suppression and extinguishment for the test conditions and "commodity" arrangement in the $10,000 \mathrm{~kW}-$ Scale Flammability Apparatus, the calculations show that chemical and convective heat release rates need to be reduced to or below about 4 and $2 \mathrm{MW}$, respectively. The calculations show that for "Class I commodity", this condition is expected to be achieved quite easily by applying $65 \mathrm{me} / \mathrm{m}^{2}-\mathrm{s}\left(0.1 \mathrm{gpm} / \mathrm{ft}^{2}\right)$ of water to the top of the "commodity" arrangement. For "Group A plastic commodity", which has the highest chemical heat release rate, the calculations show that a water application rate of about $323 \mathrm{me} / \mathrm{m}^{2}-\mathrm{s}\left(0.48 \mathrm{gpm} / \mathrm{ft} \mathrm{t}^{2}\right)$ is needed for effective fire control, suppression and extinguishment. Thus, higher the heat release rate (fire propagation velocity) higher is the water application required for effective fire control, suppression and extingu:shment. Reduction in the heat release rate by passive fire protection agents, thus would be complementary to water.

The data in Fig. 8 show that in the presence of agent A, "Group A Plastic Commodity" behaves similarly to "Class IV Commodity" and in the presence of agent B, "Group B plastic commodity" behaves similarly to "Class II commodity". The calculations show that for effective fire control, sup pression and extinguishment, water application rates of about $323 \mathrm{me} / \mathrm{m}^{2}-\mathrm{s}$ $\left(0.48 \mathrm{gpm} / \mathrm{ft}^{2}\right)$ and $280 \mathrm{ml} / \mathrm{m}^{2}-\mathrm{s}\left(0.42 \mathrm{gpm} / \mathrm{ft}^{2}\right)$ would be required for "Group A and $B$ plastic commodities", whereas with passive fire protection using agents $A$ and $B$, the water application rate required would be reduced to about $280 \mathrm{ml} / \mathrm{m}^{2}-\mathrm{s}\left(0.42 \mathrm{gpm} / \mathrm{ft}^{2}\right)$ and $205 \mathrm{ml} / \mathrm{m}^{2}-\mathrm{s}\left(0.30 \mathrm{gpm} / \mathrm{ft}^{2}\right)$, a very significant decrease for commercial/ industrial fire protection. The results thus indicate that effective passive fire protection techniques, if developed by incorporation of the agents chemically into materials and products, would be complementary to the active fire protection techniques for commercial/industrial fire protection.

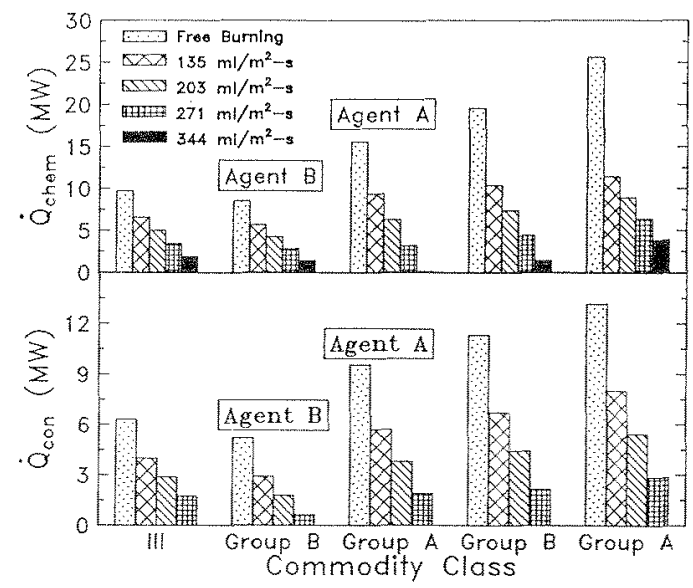

Figure 7. Calculated Chemical and Convective Heat Release Rates for Commodities at Various Water Application Rates. 


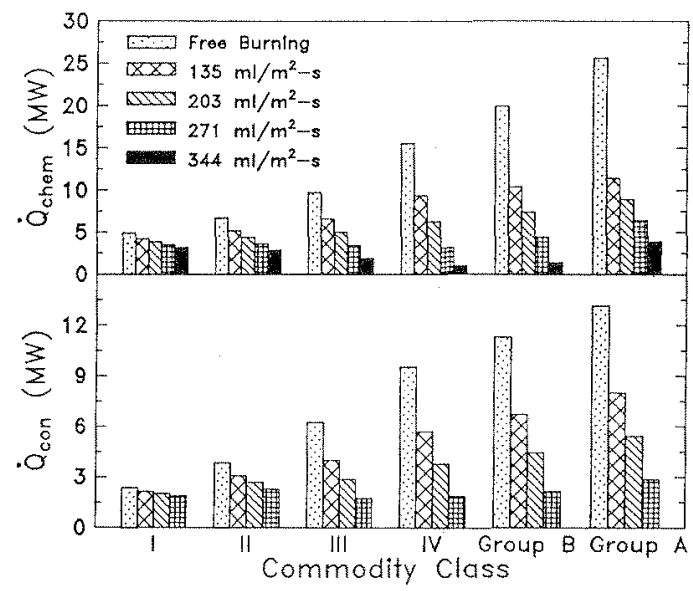

Figure 8. Calculated Chemical and Convective Heat Release Rates for Commod.. ities Including Treated and Untreated Groups $A$ and $B$ Plastics Commodity at Various Water Application Rates. Agents A and B are Passive Fire Protection Agents.

\section{CONCLUSIONS}

1. It is possible to develop effective passive fire protection techniques, by incorporating the agents chemically into materials and products, which are complementary to active fire protection techniques for commercial and industrial applications for fire control, suppression and extinguishment.

2. The effective passive fire protection techniques utilizing chemical modifications of the materials and fire retardant additives increase resistance to: a) ignition and fire propagation, by increasing the critical heat flux for ignition and thermal response parameter, and b) fire propagation by reducing the heat release rate.

3. The effective passive fire protection techniques, utilizing chemical modifications of the materials and fire retardant additives interacting in the solid phase are also expected to be effective in reducing non-thermal fire hazards (hazards due to smoke, toxic and corrosive products) due to the reduced rate of generation of fire products.

\section{ACKNOWLEDGEMENT}

The authors wish to thank Mr. S.D. Ogden for performing the experiments.

\section{REFERENCES}

1. Tewarson, A., "Combustion of Polymeric Materials: A Review", Prog. Energy Combus. Sei. (to be published).

2. "Where There's Smoke", Factory Mutual Research Corp. Update, Casaccio, E.K. (Ed.). Vol. 2, No. 2. Factory Mutual Research Corp., Norwood, MA, May 1987 . 
3. Rasbash, D.J., "The Extinction of Fire with Plain Water: A Review", First Safety Science Proceedings of the First International Symposium, p. 1145. Hemisphere Publishing Corp., NY, NY, 1986.

4. Heskestad, G.H., "The Role of Water in Suppression of Fire: A Review", J.Fire and Flammability, 11, 254, 1980.

5. Kanury, A.M., "Flaming Ignition of Solid Fuels", Chapter 1-21, p. 1-326, The SFEE Handbook of Fire Protection Engineering. DiNenno, P.J., (Ed.). The National Fire Protection Association Press, Quincy, MA 1988.

6. Quintiere; J.G., "Surface Flame Spread", Chapter 1-24, p. 1-360. The SFEE Handbook of Fire Protection Engineering. DiNenno, P.J., (Ed.). The National Fire Protection Association Press, Quincy, MA 1988.

7. Tewarson, A., and Khan, M.M., "Flame Propagation for Polymers in Cylindrical Configuration and Vertical Orientation", Twenty-Second Symposium (International) on Combustion, p. 1231. The Combustion Institute, Pittsburgh, PA 1988.

8. Specification Test Standard Cable Fire Propagation, Class No. 3972. Factory Mutual Research Corp., Norwood, MA 1989.

9. Loss Prevention Data Technical Advisory Bulletin Cable Flammability, 5-31, 4-5. Factory Mutual Research Corp., Norwood, MA, Nov 1989.

10. Harkleroad, M., Quintiere, J.G., and Walton, W., "Radiative Ignition and Opposed Flow Flame Spread Measurements on Materials", Technical Report DOT/EAA/CT-83/28. Aug 1983. National Technical Information Service, Springfield, VA 22161.

11. Tewarson, A., "Experimental Evaluation of Flammability Parameters of Polymeric Materials", Flame Retardant Polymeric Materials, Chapter 3, p. 97. Lewin, M., Atlas, S.M., and Pearce, E.M. (Eds.). Plenum Press, NY, NY 1982.

12. Tewarson, A., "Generation of Heat and Chemical Compounds in Fires, Fire Protection Handbook of the Society of Eire Protection Engineering, Chapter $1-13$, p. 179. DiNenno, P.J., (Ed.). The National Fire Protection Association Press, Quincy, MA 1988.

13. Tewarson, A., Lee, J.L., and Pion, R.F. "The Influence of Oxygen Concentration on Fuel Parameters for Fire Modeling", Eighteenth Symposium (International) on Combustion, p. 563. The Combustion Institute, Pittsburgh, PA 1981.

14. Lee, J.L., "Extinguishment of Rack Storage Fires of Corrugated Cartons Using Water," Eirst Safety Science Proceedings of the Eirst International Symposium, p. 1177. Hemisphere Publishing Corp., NY, NY 1986.

15. Chicarello, P.J., and Troup, J.M.A., "Fire Products Collector Test Procedure for Determining the Commodity Classification of Ordinary Combustible Products," Technical Report J.I. OROE5.RR, Eactory Mutual Research Corp., Norwood, MA, March 1990.

16. "Advances in Commodity Classification," Record, Casaccio, E.K. (Ed.), Vol. 67, No. 2. Eactory Mutual Research Corp., Norwood, MA, Mar/Apr 1990. 
